Evidence and Counter-Evidence, Festschrift Frederik Kortlandt, Volume 2 SSGL 33, Amsterdam - New York: Rodopi, 2008, 93-100

\title{
LIVING (HAPPILY) WITH CONTRADICTION
}

\author{
KAREN STEFFEN CHUNG
}

Grammatical analysis contains many contradictions and inconsistencies that we cannot easily rationalize away. And yet we seem to be able to live with these contradictions quite well - when we are even aware of them - as far as language use goes. Are we just not yet advanced enough to explain some really common phenomena? Or do the unresolvable contradictions stem from previous analyses that have locked us into narrow-minded prejudices? Or do some phenomena by nature harbor contradictory features and thus defy classification one way or the other? This essay will look at just one such paradox of grammar, the use in English of -ing verb forms after aspectual verbs such as to finish and to continue, and also gerunds in general.

Aspectual verbs like to start, to stop, and to continue are not complete verbal notions in themselves; they require either an explicit additional verb as a complement (start to sing or start singing, stop talking, continue working) or an implied action that is clearly understood by the listener or reader (Start [writing your essay]; Will you please just stop? [making all that noise]; Please continue [telling your story]). Aspectual verbs can also take a nominal object (He's just started a new book.); though in this case too there is an implication that some action (e.g. reading) has been started, stopped or continued.

There are three types of -ing-suffixed words in English: (1) straightforward nouns, like clothing, lining, and inning; (2) present participles, like hopping in The frog is hopping across the road., and working in I'm still working on it.; and (3) gerunds, or verbal nouns, like singing in Her singing is beautiful, and traveling in I do a lot of traveling for work.

Historically, gerunds and present participles did not always share the same external form. In the Old English period, participles were strictly verbal and ended in -ende which later became -inde. -ing, which was etymologically unrelated to -ende and -inde, was an ending used only in nouns of action. The gerund did not appear until the middle of the $14^{\text {th }}$ century (Broderick 2000: 1). By this time, the participle had come to be pronounced and written -inge, and it thus merged with the gerund form.

Present participles, which refer to an ongoing action, are unequivocally verbs in function (the dog is barking) as well as origin, though they can also 
be used adjectivally (the barking dog). Like adjectives, present participles can follow finite forms of the verb to be (the boy is reading; compare with the boy is studious). Despite the similar distribution in some contexts of adjectives and present participles, most people would not claim that reading in the boy is reading is an adjective. We can view the auxiliary verb is as similar to modal verbs, which are defined as expressing "meanings of judgments of possibility, probability, necessity... or permission, obligation, volition" (Ebensgaard Jensen 2004) ${ }^{1}$, e.g. can in the boy can read. Both to be and modal verbs are complemented by a non-finite form of the main verb, though modals take a bare infinitive while to be takes an -ing verb form.

Though one is classified as a verb and the other as a noun, we can see some similarities between present participles and gerunds: both are composed of a non-finite verb form and are thus objectified and to some degree removed from the immediate action, as opposed to a finite verb, which is generally marked for person and tense, and often refers to a concrete instance of a specific situation.

If one starts $x$, regardless of whether $x$ is a noun, an -ing verb, or a to infinitive, we interpret $x$ as a grammatical object of the aspectual verb. The aspectual verb has somehow acted on $x$, and $x$ is the receiver of this action. Because it is a grammatical object, the complement of an aspectual verb is generally classified as a gerund or verbal noun in traditional grammar.

We must next ask what an "object" is. One source ${ }^{2}$ defines a direct object as "the noun, noun group or pronoun which receives a verb's action", saying explicitly that a direct object must be a kind of noun. MerriamWebster (2005) adds no such restriction, and defines it thus: "a word or phrase denoting the goal or the result of the action of a verb."

While -ing forms used after aspectual matrix verbs are generally considered gerunds, unlike ordinary nominal objects, they themselves can also take a direct object if they are transitive: John continued eating his supper. This creates a kind of conflict, since we are not dealing with two objects of the aspectual verb, but an object of the aspectual verb and an object of the verb complement, which share the same subject. Obviously gerunds, if that is what these are, are not typical nouns, since typical concrete nouns like table and sun, abstract ones like freedom and frustration, and proper nouns like Mrs. Walker and Belize cannot take grammatical objects. So it is clear that gerunds retain important verbal properties.

\footnotetext{
${ }^{1}$ http://www.humaniora.sdu.dk/ kej/intro5.pdf, 25 May 2005

2 http://englishplus.com/grammar/00000017.htm, 25 May 2005
} 
On this issue, Hudson (2003: 611) concludes this: "English gerunds are indeed just what the traditional grammarians said: single words which are both verbs and nouns...there is no need to assume separate verbal and nominal nodes in order to prevent verbal and nominal characteristics from conflicting, because English is organised in such a way that these characteristics are always orthogonal: nominal features are exclusively concerned with relations external to the gerund phrase, and verbal features with its internal patterns."

"External" here means that an aspectual verb needs to take a nominal object, but -ing forms can otherwise behave like verbs and themselves take objects. And although gerunds are non-finite, they retain their semantic sense of dynamism and action as opposed to the static nature of nouns.

In general, sentences constructed with aspectual verbs plus verb "objects" retain most of their meaning when the aspectual verb is omitted: John continued eating. is not too different from John was eating. or even John ate., though with the removal of the externally-imposed operation which adds the meaning of 'beginning', 'continuing', and so on, the "nouns" are again unequivocally verbs. Yet our conceptualization of the content of the main verb is largely the same in either case, with only minor modifications.

Since the -ing forms and the infinitive complements of aspectual verbs clearly must fulfill both verbal and nominal functions, some researchers have attempted to unify the two under a single definition, or a "monosemic" analysis. Broderick (2000:9) describes how his friend Charles Ruhl, if he were to take on this problem, would collect every example he could find of -ing forms, put them on cards, then arrange them from ones that are clearly "nouns" to those that are inarguably "verbs". He says that "the first cards might contain -ing forms that are obviously derived nouns (forms like wedding, meeting, blessing). Soon you might be reading sentences that clearly contain "gerunds", but you would be hard-pressed to point out just which card marks the transition from derived noun to "gerund". And the rich set of data would similarly make it difficult to transition from "gerund" sentence to "present participle" sentences and then to sentences with derived adjectives such as cunning, willing, daring, and hulking... In short, you would have an existential experience of the monosemy of the forms."

Though an interesting intellectual exercise, bringing both forms under one definition does not mean that the two are in fact the same form. We may find enough things in common between the two that we can treat them as subtypes under one concept, e.g. "-ing forms". But they will behave differently when used in each of their respective functions. The 
-ing verb forms will still adjust their properties, and their classification as "gerund" or "participle", according to context and need.

One concrete way in which participles and gerunds have distinct external marking is found in prosody, when the two types are used as adjectives in compounds and phrases. An example: In smoking gun, smoking is clearly an adjective derived from a present participle; it is what the gun is in the process of doing: emitting smoke. In this type of construction, both elements are stressed, since both are content words and they do not form a lexified expression.

In smoking room, on the other hand, smoking is unambiguously nominal, thus a gerund, and not a present participle. Though the room may indeed be giving off smoke, as a smoking house would be during or after a fire, here smoking describes a function or purpose of the room: a smoking room is 'a room set aside for people to smoke in'. This is a nominal compound in which the two elements taken together are conceived of as a single notion and word, and a single word in theory should have only one primary stress, which is in fact the case; there is no stress on the modified element, room.

We could go further and distinguish gerunds that are "more nominal" from ones that are "less nominal". An example is found in the use of explicit nominal markers, such as articles and prepositions, together with -ing forms. Cooking is a gerund in Cooking is not allowed. But it can take a direct object, e.g. Cooking food is not allowed., pushing cooking perhaps more to the verbal side. However, one has a sense of its becoming more nominal when a definite article is added: The cooking of food is not allowed, which in turn calls for a preposition after it, something not required when the article is not present. This is an example of distributional factors distinguishing, or influencing the perception of, one "degree" of gerund from another.

Might it be our enslavement to the ideas of "verb" and "noun" that is causing the trouble? In the languages of the world, verbs and nouns, along with adjectives/modifiers and perhaps particles, tend to be the basic, recurring word types, and other word types are often some kind of variation on these. As long as we accept that noun and verb are the useful core concepts we believe them to be, we may have to also accept the inconveniences they bring to certain parts of the grammar, due to imposition of the preconceived ideas of "object" and "action" inherent in the notions of "noun" and "verb" on parts of speech that are not quite one or the other.

Like with any other system of analysis, the rules are designed for the mainstream, or more accurately, for the cases that are more easily described and pigeonholed. There are always some cases that "fall in the 
cracks". In the case of the law, one cannot stipulate every single eventuality, and it is ultimately up to the individual, lawyers, the courts and society to decide what is most in keeping with "the spirit of the law". Something similar happens in grammar, when we must decide whether, for example, the spirit to be emulated is that of the syntax or the semantics of a construction. In a formalized system, the syntax is likely to win out, since the chief aim of syntax is to provide an explicit set of rules for how words can be combined to output correctly formed utterances, or conversely, how to rationalize and explain the composition of an existing well-formed utterance. Semantics, on the other hand, can be defined as "the meaning of a word, phrase, clause, or sentence, as opposed to its syntactic construction" ${ }^{\prime 3}$. Thus it can be imagined that usage, or the syntax, may pull an analysis one way, and semantics, the other. So perhaps a fundamental task of linguistic analysis is to somehow reconcile the two, better than has been done so far, especially in the less straightforward cases.

In our effort to construct a clean, unambiguous grammar, we often forget how arbitrarily we use language to chop reality into bits, ones that we can classify and manipulate to reconstruct for others and ourselves the external reality of the world, and the internal reality of our thoughts. While there is necessarily distortion in the process, we see language reasserting the fact that it, like reality itself, is a continuum of things and events that are in fact not separated from each other at all; they are inextricably interconnected. The separations are simply a necessary pre-processing we do to organize and communicate information, much as we eat our food in bites rather than stuff a whole meal in our mouth at once. And just as we have more and less typical representatives of all kinds of semantic categories in the world, e.g. sparrows and robins are more typical of the category "birds" than are ostriches and kiwis, we have more and less representative nouns, verbs and adjectives, which are furthermore multifunctional.

We may also sometimes forget that categories which supposedly belong to the same level of analysis, and that we conceive of as "either-or" choices, routinely overlap. An obvious example is how book in bookcase would be called an "adjective", though we are very aware of its nounness, and how that nounness doesn't disappear when it is "used as" an adjective. However is generally considered adverbial, though it clearly also functions as a conjunction. Grammars are full of such examples.

Prescriptivists like Fowler (1908) are often uneasy with dual or multiple category membership, and may attempt to reduce category-straddling

${ }^{3}$ http://rinkworks.com/words/linguistics.shtml, 25 May 2005 
by decree. Their pronouncements may catch on in education systems, since educators often like to provide clear answers that lend themselves to convenient testing. In his King's English, Fowler rejects the "fused participle" treatment of gerunds - i.e. that these forms are simultaneously gerunds/nouns and participles/verbs at the same time - and insists that sentences such as this: You may rely upon me doing all in my power. (Sir W. Harcourt) ${ }^{4}$, for example, be revised to: You may rely upon my doing all in my power., so that through use of the possessive, gerunds become as consistently nominal as he can make them. People may end up actually talking and writing according to Fowler-type rules, but it is usually with a feeling that one is doing what one has been told is "right" rather than what sounds most natural.

Blevin (2003: 15) on the other hand is happy with multiple roles for grammatical forms. He writes: “(...) it is perhaps also worth asking why violations of phrasal endocentricity are regarded as so deeply problematic. A system without any such violations is more consistent and can therefore be described somewhat more economically. But what reason is there to believe that this notion of economy is in any way relevant to the acquisition or use of language? Surely learners can come to recognize that a language contains a nominal construction headed by a verbal subconstituent, and speakers can produce and interpret this construction appropriately. And why should such a pattern, once established in a language, not remain stable, at least for some extended period of time?"

The great flexibility and adaptability of the linguistic system and its components does not mean that the study of grammar should be abandoned or that it is irrelevant. Structure is necessary to somehow systematize the large number of fragmented semantic "bits" we must deal with. But grammatical and morphological structure must serve the needs of the moment, and should not be treated as a sacred shrine whose form, or any given analysis of it at some given point in time, must be preserved at all costs.

Bauer (2004: 8) aptly sums up a realistic view of the function of linguistic structure: “...it could be argued that one of the functions of morphological constructions is to allow you to put 'the same word' into different syntactic environments." There are many different syntactic environments, and we cannot easily maintain a distinct morphological form for every single possible environment and function. Morphological and syntactic forms will appear in response to need as it comes up, and a form used in one function may be called on to fill another function that is sensed to be

${ }^{4}$ http://www.bartleby.com/116/212.html, 25 May 2005 
somehow comparable to the first. How similar does one function have to be to another for this to happen? It can vary widely. Linguists are left with the job of trying to sort out the patterns that emerge in all their diverse and somewhat haphazard glory. It is a fascinating task, but no one should be upset when the pieces don't seem to immediately fit together, or to unfailingly follow the rules we have so painstakingly derived regarding them, or even to belong to the same part of the puzzle. Some parts will be easy and even logical and consistent; others will not. Just because language is as systematic as it very often is does not mean all the other parts of it will be systematic all the time, or that they should be so. Expectation of the unexpected and the not-easily-rationalized is in fact something that needs to be built into our approach and analysis. Inconsistency and irreconcilability should be appreciated as the things of beauty and wonder that they are, rather than being viewed as a spanner in the works which "ruins" our beautiful analyses.

National Taiwan University

\section{REFERENCES}

Adams, Larin K.

1999 Complex events and the semantics of -ing sentential complements. Dissertation, Northwestern University, June 1999.

Bauer, Laurie

2004 A glossary of morphology. Washington D.C.: Georgetown Press.

Blevins, James $\mathrm{P}$.

2003 "Remarks on gerunds". O. Orgun \& P. Sells (eds.), Research Centre for English and Applied Linguistics. In: O. Orgun \& P. Sells (eds.), Morphology and the web of grammar: Essays in memory of Steven G. Lapointe. Stanford: CSLI Publications.

Broderick, John P.

$2000 \quad$ "Toward a "monosyntactic" (and monosemic?) analysis of -ing forms in English". Address delivered at the Sixty-third Meeting of the Southeastern Conference on Linguistics (SECOL LXIII), Birmingham, AL, November 11, 2000.

http://courses.lib.odu.edu/engl/jpbroder/2000d\%5Bingforms\%5D.doc

Duffley, Patrick J.

1992 The English infinitive. English Language Series. New York: Longman.

2003 "Les conditions de production de l'effet de sens 'imperfectif' avec la forme en -ing de l'anglais". Langages 149, 86-99.

Duffley, Patrick J., and Rachel Tremblay

2004 "The infinitive and the -ing as complements of verbs of effort". English studies 75(6), 566-575. 
Ebensgaard Jensen, Kim.

2004 Kim Ebensgaard Jensen's Website. Language introduction lecture notes, University of Southern Denmark, Kolding, Sep. 16. 2004.

http://www.humaniora.sdu.dk/ kej/intro5.pdf

Fowler, H. W.

1908 The King's English. $2^{\text {nd }}$ ed. Chapter II. Syntax: Participle and gerund, Participles, The gerund. Oxford: Clarendon press, 1908. New York: bartleby.com, 1999. http://www.bartleby.com/116/212.html

Hudson, Richard

2003 "Gerunds without phrase structure". natural language and linguistic theory. 21, 579-615.

Malouf, Robert

$1996 \quad$ "A constructional approach to English verbal gerunds." In: Proceedings of the Twenty-second Annual Meeting of the Berkeley Linguistics Society, 255266.

2000 "Verbal gerunds as mixed categories in HPSG." In: R. Borsley (ed.), The Nature and Function of Syntactic Categories, 133-166. New York: Academic Press.

Merriam-Webster

2005 Merriam-Webster online dictionary and thesaurus. http://www.mw.com/home.htm, 25 May 2005. 